\title{
As Alternativas às Penas e às Medidas Socioeducativas: estudo comparado entre distintos modelos de controle social punitivo
}

\author{
Salo de Carvalho ${ }^{1}$ \\ Mariana de Assis Brasil e Weigert ${ }^{2}$
}

\begin{abstract}
Resumo: O artigo apresenta o quadro normativo de alternativas às penas e às medidas (socioeducativas e de segurança) e os mecanismos de diversificação processual no direito brasileiro no Estatuto da Criança e do Adolescente (Lei n. 8.069/90), na Lei dos Juizados Especiais Criminais (Lei n. 9.099/95) e na Lei das Penas Alternativas (Lei $\mathrm{n}$. 9.714/78). A partir de uma abordagem comparativa, avalia os sistemas de direito penal e de direito juvenil de resposta ao ilícito, enfatizando as sanções aplicáveis ao adolescente em conflito com a lei. Concretiza o estudo na análise da prestação de serviço à comunidade, problematizando a tensão entre as sanções alternativas ao encarceramento e a ampliação da rede do poder punitivo na contemporaneidade (punitivismo).
\end{abstract}

Palavras-chave: Penas. Medidas Socioeducativas. Penas Alternativas.

\begin{abstract}
The article presents the normative framework of alternatives to sanctions and the mechanisms of procedural diversification in the Brazilian Law, more specifically in laws $8.069 / 90,9.099 / 95$ and 9.714/78. In a comparative approach, it evaluates both the penal law system and the juvenile law system of response to offenses, highlighting the penalties applicable to young offenders in conflict with the law. The study analyzes the process of community service, problematizing the existing tension between alternative sanctions to incarceration and the expansion of the punitive power in the contemporary world (punitivism).
\end{abstract}

Key words: Punishment. Youth Criminal System. Alternative Sanctions.

1 Possui Pós-doutorado em Criminologia pela Universidade Pompeu Fabra (Barcelona - Espanha). Doutor em Direito pela Universidade Federal do Paraná. Mestre em Direito pela Universidade Federal de Santa Caratina. Professor adjunto do Departamento de Ciências Penais da Universidade Federal do Rio Grande do Sul. Professor titular do Departamento de Ciências Criminais da PUC-RS.E-mail: salo.carvalho@uol.com.br.

2 Doutoranda em Direito Público e Mestre em Criminologia e Execução Penal pela Universidade Autônoma de Barcelona (Espanha). Doutoranda em Psicologia Social e Institucional pela Universidade Federal do Rio Grande do Sul. Mestre em Ciências Criminais pela PUC-RS. Graduada em Direito pela PUC-RS. Professora de Direito Penal e Criminologia na UniRitter.E-mail:mabw@terra.com.br.

Recebido em: 29/09/2011.

Revisado em: 27/04/2012.

Aprovado em: 02/05/2012. 


\section{Introdução}

O presente estudo apresenta o quadro normativo brasileiro de alternativas às penas e às medidas (socioeducativas e de segurança) e as formas legais previstas para diversificação processual que permitem pensar distintas respostas jurídicas aos conflitos criminalizados.

Em razão da proximidade dos institutos que envolvem a matéria, o trabalho opta por uma metodologia comparativa, de forma a apresentar ao leitor um panorama geral dos sistemas de penas e de medidas no direito brasileiro. Enfatiza, contudo, a construção de um modelo próprio de justiça juvenil com mecanismos legais autônomos de sanção ao adolescente em conflito com a lei condenado pela prática de ato infracional.

A análise é construída a partir do marco principiológico constitucional para, em um segundo momento, observar, na legislação ordinária, sobretudo o Estatuto da Criança e do Adolescente (Lei n. 8.069/90), a Lei dos Juizados Especiais Criminais (Lei n. 9.099/95) e a Lei das Penas Alternativas (Lei n. 9.714/78).

A partir da análise concreta da prestação de serviço à comunidade como espécie de sanção restritiva de direito, o estudo busca problematizar a tensão entre as sanções alternativas ao encarceramento e a ampliação da rede do poder punitivo na contemporaneidade (punitivismo).

O trabalho - apesar de perceber o tenso debate e os efeitos práticos da manutenção da lógica da doutrina da situação irregular em detrimento da doutrina da proteção integral - não ingressa na análise específica da autonomia do sistema de justiça juvenil, das teorias de fundamentação das medidas socioeducativas ou das teorias de fundamentação das penas. O enfrentamento dessas questões fundacionais sobre os sistemas e os princípios de justificação do poder punitivo - questões importantes para a compreensão da lógica inquisitiva que orienta a interpretação dos direitos e das garantias dos adolescentes em conflito com a lei - segue a postura agnóstica manifestada em estudos anteriores que projeta atuações práticas centradas na elaboração ou qualificação de instrumentos voltados à 
redução dos danos provocados pela incidência inábil do potestas puniendi (CARVALHO, 2011, p. 137-154; CARVALHO, 2007, p. 3-28) ${ }^{3}$

O objetivo do estudo não é, portanto, debater os fundamentos da intervenção sancionatória como resposta ao crime (justiça penal de adultos) ou ao ato infracional (justiça penal juvenil). Em realidade, a ideia do artigo é problematizar as formas de exercício concreto do poder punitivo na área da infância e do adolescente com a finalidade de projetar estratégias de potencialização dos direitos e garantias neste enfrentamento com as distintas formas de intervenção das agências de controle social. Mais especificamente: o texto procura apresentar as alternativas normativas ao sistema punitivo e avaliar suas formas de otimização para que os substitutivos ao encarceramento não sejam apenas aditivos. Logicamente esta opção metodológica revela uma postura político-criminal, identificada, conforme apontado, com a teoria agnóstica e o garantismo jurídico. Todavia não é neste plano de debate que o texto encontra seu campo de indagações.

O espaço que permite a aproximação, mas não os confunde, do direito penal com o direito infracional sancionador é o ilícito. A previsão

3 A autonomia do direito infracional em relação ao direito penal, adotada a partir da perspectiva agnóstica, é defendida, dentre outros, por Alexandre Morais da Rosa: “[...] necessário, assim, discutir-se uma teoria fundamentadora/justificadora da resposta estatal. Entretanto, a medida socioeducativa, longe de uma fundamentação jurídica, possui somente uma justificação política, de ato de força estatal. É afastada qualquer justificação, retributiva ou preventiva, da medida, conforme explicita o Garantismo Jurídico, na pena tupiniquim de Carvalho. Relegada a discussão abolicionista (Foucault, Mathiesen, Christie e Hulsman), assume-se a postura garantista-infracional, informada pelo Princípio da Secularização e da Laicização do Estado, da 'Teoria Agnóstica' da medida socioeducativa. Esta teoria, percebendo a imposição como ato de poder, tal qual a guerra, imputa ao direito infracional a finalidade de redução das violências praticadas pelo Estado. Existiria, portanto, uma dupla funcionalidade da medida socioeducativa. Primeiro, impedir a vingança privada (abusiva e espúria) [...] em segundo lugar, restringindo a manifestação do poder político estatal, isto é, a medida socioeducativa, de maneira arbitrária (sem limites) e violando Direitos Fundamentais, nos exatos limites da estrita legalidade." (CARVALHO, 2007, p. 202-203). Em momento seguinte conclui o referido autor: "[...] isso porque pela construção efetivada, o fundamento da medida socioeducativa é agnóstico, como indica Carvalho, sendo antidemocrática qualquer pretensão de reforma interior ou moral do adolescente na linha fascista da Defesa Social." (ROSA, 2007, p. 221) 
constitucional de inimputabilidade aos adolescentes em conflito com a lei exclui a possibilidade de responsabilização penal - a imputabilidade que, como um dos elementos da culpabilidade (capacidade), é pressuposto de existência do delito ${ }^{4}$. No entanto todos os demais elementos do crime estão presentes na conduta definida como ato infracional.

Em função dessa zona de convergência que aproxima o direito penal do direito juvenil, o artigo abordará instrumentalmente as ideias de conduta ilícita (ilícito-típico ou injusto penal) e de sanção, de forma a identificar campos de similitude entre crime e ato infracional e entre pena e medida socioeducativa, projetando, no contexto do controle social institucionalizado, formas alternativas de gestão (processual) e resposta (sanção) das situações-problema produzidas por adolescentes, jovens e adultos em conflito com a lei.

\section{O Sistema Brasileiro de Responsabilização Jurídica pela Prá- tica de Atos Ilícitos: penas e medidas}

A Constituição estabelece formas distintas de responsabilização pela prática de condutas definidas em Lei como crime. $\mathrm{O}$ artigo $5^{\circ}, \mathrm{XX}$ XIX, da Constituição molda o sistema jurídico-penal a partir do princípio da legalidade, fixando a pena como resposta ao ilícito - “[...] não há crime sem lei anterior que o defina, nem pena sem prévia cominação legal." (BRASIL, 1988, art. 5)

4 A teoria do direito penal (dogmática penal), projetada na estrutura normativa dos países de tradição jurídica romano-germânica, define crime como conduta típica (com correspondência a uma norma ou tipo penal incriminador), ilícita (realizada sem o amparo de uma causa de justificação) e culpável (atributo do autor da conduta que pressupõe capacidade (imputabilidade), potencial consciência da ilicitude e exigibilidade de conduta diversa). Na ausência de um dos atributos inexiste delito. No caso das condutas praticadas por adolescentes em conflito com a lei, o artigo 228 da Constituição estabelece ausência de capacidade para a culpabilidade (imputabilidade) aos menores de 18 (dezoito) anos. Todavia define o ato infracional como a conduta prevista como crime (conduta típica), sendo passível a presença de causas de exclusão da ilicitude no ato do jovem (p. ex., ato em legítima defesa ou estado de necessidade). Dessa forma, o conceito de ilícito (injusto penal) é plenamente aplicável aos adolescentes, situação que autoriza o estudo comparativo sob estes pressupostos. 
Como consequência da prática de um delito, a pena tem como destinatário o sujeito capaz (imputável). A personificação do ilícito impõe e limita a sanção: "[...] nenhuma pena passará da pessoa do condenado [...]" (BRASIL, 1988, art. 5)

Legalidade e pessoalidade, portanto, são os princípios centrais que orientam o sistema de responsabilização penal e representam os pilares de sustentação do sistema de garantias dos direitos fundamentais. Com o fechamento do horizonte de incriminação em uma lei penal prévia e taxativa, o vínculo entre a conduta delitiva e a sanção penal se estabelece a partir da identificação do autor do fato punível. A imputação recai apenas sobre aquele sujeito imputável que deu causa ao resultado ilícito (imputação objetiva do resultado - artigo 13, caput, Código Penal), a partir de uma ação ou omissão dolosa ou culposa (imputação subjetiva do resultado - artigo 18, Código Penal).

A ideia moderna de responsabilidade penal é um dos desdobramentos jurídicos da teoria do contrato social, que tem como pressuposto que o sujeito da obrigação tenha capacidade de opção livre e consciente dos ônus decorrentes da sua conduta (pena). A definiçãa dos critérios de capacidade (imputabilidade) penal no ordenamento jurídico brasileiro segue dois parâmetros normativos: o etário e o psíquico. ${ }^{5}$ Assim, a imputabilidade do sujeito - imputabilidade entendida como capacidade para a culpabilidade - compreende a ultrapassagem dos limites etários legais e a ausência de sofrimento psíquico que obstaculize a consciência do ilícito ou impossibilite uma conduta adequada às normas legais.

5 Em que pese a doutrina adotar a terminologia da inimputabilidade biopsicológica, de forma a diferenciar os transtornos mentais de origem orgânica daqueles psicológicos, adota-se a classificação sugerida por Paulo Queiroz (2011, p. 324): “[...] é de convir, inclusive, quanto à impropriedade da expressão 'método biopsicológico', porque em realidade nem o estado é biológico - se em alguns casos o fato está biologicamente fundamentado - nem a capacidade é psicológica - mas uma construção normativa, de sorte que se trata, mais exatamente, de um método psíquico-normativo ou psicológiconormativo: o psicológico se refere aos estados psíquicos capazes de comprometer a capacidade de compreensão, enquanto o normativo diz respeito à capacidade, que não é um estado psíquico, mas uma atribuição." 
Nesse sentido, determina o caput do artigo 26 do Código Penal (1940) que

[...] é isento de pena o agente que, por doença mental ou desenvolvimento mental incompleto ou retardado era, ao tempo da ação ou da omissão, inteiramente incapaz de compreender o caráter ilícito do fato ou de determinar-se de acordo com esse entendimento.

Às hipóteses de inimputabilidade psíquica é agregada a inimputabilidade etária: "[...] os menores de 18 (dezoito anos) são penalmente inimputáveis, ficando sujeitos às normas estabelecidas na legislação especial." (CÓDIGO PENAL, 1940, art. 27)

No âmbito constitucional, cujo texto é posterior à Reforma do Código Penal de 1984, houve a reprodução dos critérios de inimputabilidade etária no artigo 228, padecendo de injustificável omissão em relação à inimputabilidade psíquica.

Em relação aos inimputáveis etários que praticaram atos ilícitos, a Constituição estabeleceu um critério negativo, ou seja, não criou um sistema próprio e explícito de princípios similar ao das penas. De forma distinta, limitou-se a restringir a possibilidade de responsabilização penal aos menores de 18 (dezoito) anos, determinando a regulamentação dos requisitos de responsabilização em Lei ordinária.

No entanto importante destacar que a inexistência de um corpo principiológico especifico destinado a regrar as formas de responsabilidade jurídica dos menores de 18 (dezoito) anos não obstaculiza a incidência da estrutura de garantias previstas aos imputáveis autores de delitos. Pelo contrário, é exatamente em razão da situação de vulnerabilidade que devem ser assegurados aos jovens em conflito com a lei todos os direitos individuais que conformam o sistema jurídico-penal de garantias dos adultos que praticaram delitos - garantias relativas aos requisitos legais de imputação do ato ilícito (ato infracional); garantias relativas à efetivação do devido processo legal (processo infracional); garantias relativas à aplicação e à execução das sanções (medidas socioeducativas); e garantias relativas aos critérios de aplicação de sanções disciplinares durante a execução das medidas socioeducativas. 
A propósito, o entendimento de que a situação de vulnerabilidade impede a inserção dos adolescentes em conflito com a lei no sistema penal formal é exatamente o critério de potencialização dos direitos individuais juvenis e deveria impor critérios normativos mais rígidos de interpretação das garantias para a aplicação das respostas sancionadoras. Nesse aspecto, no momento em que as garantias deveriam ser naturalmente revigoradas na tutela dos adolescentes, percebe-se de forma injustificável que sequer há paridade em relação ao tratamento jurídico recebido pelos imputáveis, na órbita do direito material - p. ex., inaplicabilidade das causas supralegais de exclusão de tipicidade (princípio da insignificância e princípio da adequação social) e de ilicitude (consentimento do ofendido) e inabilitação das regras de exclusão da punibilidade (prescrição e indulto) - na esfera do direito processual - p. ex., limitação dos critérios de controle das condições de ação para instauração do processo por ato infracional; restrição ao direito à prova; interpretações inquisitivas em relação ao papel do interrogatório; obstaculização do direito de não produzir prova contra si mesmo; flexibilização dos critérios de reconhecimento das nulidades; minimização dos efeitos recursais na efetivação do duplo grau de jurisdição - e no campo da execução - p. ex., ausência de efetivo controle judicial da aplicação das medidas socioeducativas; inexistência de normas específicas que regulamentam faltas e procedimentos disciplinares; omissão em relação aos procedimentos cruéis e desumanos de sanção nas instituições "educacionais".

A conclusão sobre a extensão potencializada dos direitos e das garantias individuais aos adolescentes em conflito com a lei é plenamente adequada à determinação constitucional de tutela absoluta e prioritária e de salvaguarda das crianças, adolescentes e jovens contra qualquer forma de negligência, discriminação, exploração, violência, crueldade e opressão. ${ }^{6}$ Entenda-se proteção absoluta e prioritária contra qualquer forma de

6 "É dever da família, da sociedade e do Estado assegurar à criança, ao adolescente e ao jovem, com absoluta prioridade, o direito à vida, à saúde, à alimentação, à educação, ao lazer, à profissionalização, à cultura, à dignidade, ao respeito, à liberdade e à convivência familiar e comunitária, além de colocá-los a salvo de toda forma de negligência, discriminação, exploração, violência, crueldade e opressão.” (BRASIL, 1988, art. 227) 
violência ou crueldade praticada por particulares (poderes privados) ou por órgãos ou instituições do Estado (poderes públicos).

Conforme destaca Alexandre Morais da Rosa (2007, p. 7), para compreender a extensão da doutrina da proteção integral,

[...] o importante é que o adolescente envolvido em atos infracionais deve ser considerado como sujeito em desenvolvimento e com autonomia, munido de garantias infraconstitucionais e processuais. Caso contrário, perdura a concepção tutelar.

No que tange à efetivação das garantias processuais e à necessidade de harmonizar o sistema de justiça juvenil aos princípios que definem as regras do jogo no processo penal, o artigo 227, IV da Constituição, cria a

[...] garantia de pleno e formal conhecimento da atribuição de ato infracional, igualdade na relação processual e defesa técnica por profissional habilitado, segundo dispuser a legislação tutelar específica. (BRASIL. 1988, art. 227)

O critério da proteção absoluta e prioritária logicamente exclui qualquer possibilidade de a legislação tutelar específica restringir aos adolescentes os direitos e garantias que orientam as formas de responsabilização penal dos adultos.

Em relação às sanções decorrentes dos atos infracionais, a Constituição determina a

[...] obediência aos princípios de brevidade, excepcionalidade e respeito à condição peculiar de pessoa em desenvolvimento, quando da aplicação de qualquer medida privativa da liberdade (BRASIL, 1988, art. 227)

O imperativo constitucional determina a observância, por todos os atores que atuam na área da infância e da juventude, do princípio da subsidiariedade (excepcionalidade) da medida em meio fechado (internação ou semiliberdade). 
A reivindicação da efetividade dos direitos individuais previstos no artigo $5^{\circ}$, incisos XXXIX a LXIX, da Constituição, aos adolescentes que praticaram fatos ilícitos está associada à estratégia de ampliação do sistema de garantias como limite a qualquer forma de intervenção de caráter punitivo-sancionador.

Eventual interpretação restritiva dos direitos e garantias individuais aos inimputáveis provocaria situações que efetivamente são incompatíveis com o projeto constitucional de respeito aos direitos humanos. Note-se, p. ex., os efeitos terroríficos produzidos pela omissão do texto constitucional em relação à inimputabilidade psíquica e, consequentemente, sobre os limites das medidas de segurança. A questão é relevante em razão da metodologia adotada pelo Código Penal, sobretudo porque as medidas de segurança não possuem limitação temporal como as penas. ${ }^{7}$ Constatada a inimputabilidade psíquica, a medida de segurança perdura enquanto não for averiguada a cessação da periculosidade do autor (CÓDIGO PENAL, 1940, art. 97, $\S 1^{\mathrm{o}},{ }^{8}$ ). A lacuna sobre a incidência dos princípios constitucionais limitativos da pena acarreta, na realidade manicomial brasileira, a possibilidade de imposição de sanção perpétua aos usuários do sistema judiciário de saúde mental que incorreram em condutas previstas como delito.

No entanto, apesar dessa omissão, em face do inegável caráter aflitivo e punitivo das medidas de segurança, a doutrina e a jurisprudência têm avançado no sentido de ampliar os critérios de interpretação e de aplicação dos direitos e garantias dos imputáveis aos portadores de sofrimento psíquico que cometeram ilícitos. Assim, gradualmente esta modalidade de sanção passa a ser restringida em termos quantitativos (CÓDIGO PENAL, 1940, art. 75) e qualitativos (hipóteses de substituição do inter-

7 Segundo o artigo 75 do Código Penal (1940), “[...] o tempo de cumprimento das penas privativas de liberdade não pode ser superior a 30 (trinta) anos."

8 "Se o agente for inimputável, o juiz determinará sua internação (art. 26). Se, todavia, o fato previsto como crime for punível com detenção, poderá o juiz submetê-lo a tratamento ambulatorial.

$\S 1^{\circ}$ - A internação, ou tratamento ambulatorial, será por tempo indeterminado, perdurando enquanto não for averiguada, mediante perícia médica, a cessação de periculosidade. $\mathrm{O}$ prazo mínimo deverá ser de 1 (um) a 3 (três) anos." (CÓDIGO PENAL, 1940, art. 97) 
namento, medidas ambulatoriais e alta progressiva) pelos princípios que orientam as penas, sobretudo após o advento da Lei de Reforma Psiquiátrica (Lei n. 10.216/01), que obriga os Poderes constituídos a criar mecanismos de desinstitucionalização dos portadores de sofrimento psíquico.

A ampliação do sistema de garantias permite, através da interpretação conforme a Constituição, aproximar a legislação nacional de algumas experiências do direito comparado nas quais os condenados a penas e aqueles submetidos a medidas de segurança possuem isonomia no tratamento jurídico - v.g., artigo 29 e 30, Constituição de Portugal; artigo 25, Constituição da Espanha; artigo 25, Constituição da Itália. No que tange especificamente à vedação da perpetuidade das penas e medidas de segurança, a Constituição portuguesa é explícita ao prever que "[...] não pode haver penas nem medidas de segurança privativas ou restritivas da liberdade com carácter perpétuo ou de duração ilimitada ou indefinida." (PORTUGAL, 1976, art. 30,1).

\section{Espécies de Penas e Medidas no Sistema Normativo Brasileiro}

O artigo $5^{\circ}$, XLVI, da Constituição, impõe a necessidade da individualização das penas após a condenação do imputável e define as espécies de sanções criminais adotadas no Brasil -

[...] a lei regulará a individualização da pena e adotará, entre outras, as seguintes: a) privação ou restrição da liberdade; b) perda de bens; c) multa; d) prestação social alternativa; e) suspensão ou interdição de direitos. (BRASIL, 1988, art. $5^{\circ}$ )

A projeção constitucional é realizada a partir da lógica de punição direcionada aos adultos (imputabilidade etária) não portadores de sofrimento psíquico (imputabilidade psíquica). Todavia, em razão da lacuna constitucional sobre as formas de sanção aplicáveis aos inimputáveis etários (jovens em conflito com a lei) e psíquicos (portadores de sofrimento psíquico) que praticaram atos ilícitos, as espécies de sanção e, sobretudo, os limites impostos às práticas punitivas se traduzem em princípios reitores ou de orientação. 
O exemplo mais evidente é o caso anteriormente referido da ilegitimidade de execução perpétua de medida de segurança em razão de o art. $5^{\circ}$, XLVII, da Constituição, estabelecer que "[...] não haverá penas: a) de morte, salvo em caso de guerra declarada, nos termos do art. 84, XIX; b) de caráter perpétuo; c) de trabalhos forçados; d) de banimento; e) cruéis." (BRASIL, 1988, art. 5º)

Nesse cenário, é possível verificar claramente dois comandos constitucionais em relação às penas, às medidas socioeducativas e às medidas de segurança. $O$ primeiro relacionado à privação de liberdade como ultima ratio (princípio da excepcionalidade ou da intervenção mínima). A Constituição, ao estabelecer as formas de sanção, apresenta a privação de liberdade como uma dentre as penas aplicáveis, isto é, a pena de prisão compõe um sistema integrado por formas alternativas de punição juntamente com a prestação social, a suspensão ou interdição de direitos, a multa e a perda de bens. Mas, para além da previsão das formas alternativas de penas, o preceito constitucional é aberto (“dentre outras"), possibilitando que o legislador ordinário crie novas formas de resposta penal ao delito. Nesse sentido, a inovação no campo das drogas: o artigo 28 da Lei n. 11.343/06, rompendo com a lógica carcerocêntrica predominante na política criminal brasileira, estabelece como penas autônomas (a) advertência sobre os efeitos das drogas; (b) prestação de serviços à comunidade; e (c) medida educativa de comparecimento a programa ou curso educativo.

O exemplo é significativo porque a tradição do direito penal romano-germâmico moderno é desenvolvida a partir da pena de prisão (lógica carcerocêntrica). Não por outra razão as chamadas penas alternativas não são efetivamente alternativas, mas substitutivas à pena privativa de liberdade (prisão). A estrutura normativa que define crimes e impõe sanções sempre é composta pela definição da conduta proibida (preceito primário) somada à quantidade de pena (preceito secundário). As penas previstas são as espécies de prisão, excetuando o caso da Lei de Drogas, relativo ao porte para consumo pessoal - p. ex., homicídio simples: “[...] matar alguém: pena - reclusão, de seis a vinte anos [...]" (CÓDIGO PENAL, 1940, art. 121, caput); lesão corporal simples: “[...] ofender a integridade corporal de outrem: pena - detenção, de três meses a um ano [...]" (CÓ- 
DIGO PENAL, 1940, art. 129, caput); furto simples: “[...] subtrair, para si ou para outrem, coisa alheia móvel: pena - reclusão, de um a quatro anos, e multa [...]" (CÓDIGO PENAL, 1940, art. 155, caput). Nos exemplos referidos, mesmo sendo possível a substituição da prisão pela multa (caso da lesão corporal leve) ou pela pena restritiva de direitos (caso do furto simples), o juiz terá de aplicar, em um primeiro momento, a pena de prisão, situação que inegavelmente constitui um modus de pensar e de realizar o direito penal.

Todavia, a previsão constitucional da pena de prisão como apenas uma dentre as sanções penais possíveis possibilita a alteração da lógica de segregação, projeto político que orientou, no âmbito das medidas de segurança, a Lei de Reforma Psiquiátrica, e que permite pensar formas distintas da internação ou de semiliberdade no caso de constatação da prática de atos infracionais por jovens. A propósito, conforme referido, a excepcionalidade da medida privativa de liberdade é princípio orientador expresso conforme estabelecido no artigo 227, V, Constituição.

$\mathrm{O}$ segundo comando constitucional relativo às penas, às medidas socioeducativas e às medidas de segurança, que se harmoniza com o princípio da excepcionalidade, é a necessidade de efetivação de formas humanitárias de sanção, situação jurídica definida pela doutrina através do princípio da humanidade. (BRASIL, 1988, art. 5, XLVII)

Logicamente a realidade dos sistemas prisional e de internação manicomial (manicômios judiciários) e socioeducacional nega, cotidianamente, com a conivência irresponsável, comissiva ou omissiva, dos agentes dos poderes públicos (Executivo, Legislativo e Judiciário), o comando constitucional que veda a imposição de sanções desumanas (cruéis). Todavia os preceitos que determinam a efetividade dos direitos humanos possibilitam aos atores sociais comprometidos com a garantia dos direitos a criação de estratégias políticas de redução dos danos provocados pela ingerência inábil ou inquisitiva das agências de punitividade. $\mathrm{O}$ desconforto com a passividade genocida dos poderes públicos permite aos atores sociais ressignificar o preceito de vedação de penas cruéis (princípio da humanidade), transformando a abstração normativa em ação propositiva e transformadora. 
O Código Penal de 1940, ainda imerso na ideia da prisão como sanção criminal por excelência, previa como penas principais a reclusão, a detenção e a multa (art. 28). A Reforma de 1984, com o objetivo de alinhar o sistema jurídico brasileiro aos preceitos humanizadores do direito penal garantista e ciente dos malefícios do encarceramento denunciados pela criminologia crítica nas décadas de 1960 e de 1970, unificou a reclusão e a detenção sob o rótulo de pena privativa de liberdade e incorporou, junto com a multa, a pena restritiva de direitos como sanção autônoma (CÓDIGO PENAL, 1940, art. 32, II), porém substitutiva (CÓDIGO PENAL, 1940, art. 59, IV ${ }^{9}$ ). Ao regrar as espécies de penas restritivas, previu a prestação de serviço à comunidade, a interdição temporária de direitos e a limitação de final de semana (CÓDIGO PENAL, 1940, art. 43, I, II e III). As hipóteses de aplicação substitutiva das penas restritivas de direito foram posteriormente ampliadas pela Lei n. 9.714/98.

Em relação às medidas de segurança, mesmo após o advento da Lei de Reforma Psiquiátrica (Lei n. 10.216/01), o Código Penal manteve a previsão de formas de cumprimento em meio fechado (internação em hospital de custódia e tratamento psiquiátrico, conforma o artigo 96, I) e aberto (sujeição a tratamento ambulatorial, nos termos do art. 96, II), conforme a gravidade do delito e a situação pessoal do sujeito. ${ }^{10} \mathrm{O}$ artigo 99 do Código Penal (1940) determina que o recolhimento do interno deve ser realizado em estabelecimento com características hospitalares, situação que permite, ao menos em tese, harmonizar o sistema com os preceitos da reforma antimanicomial.

9 “O juiz, atendendo à culpabilidade, aos antecedentes, à conduta social, à personalidade do agente, aos motivos, às circunstâncias e consequências do crime, bem como ao comportamento da vítima, estabelecerá, conforme seja necessário e suficiente para reprovação e prevenção do crime: I - as penas aplicáveis dentre as cominadas; II - a quantidade de pena aplicável, dentro dos limites previstos; III - o regime inicial de cumprimento da pena privativa de liberdade; IV - a substituição da pena privativa da liberdade aplicada, por outra espécie de pena, se cabível". (CÓDIGO PENAL, 1940, art. 59)

10 "Se o agente for inimputável, o juiz determinará sua internação (art. 26). Se, todavia, o fato previsto como crime for punível com detenção, poderá o juiz submetê-lo a tratamento ambulatorial"'. (CÓDIGO PENAL, 1940, art. 97) 
No que tange à resposta penal aos jovens que praticaram atos infracionais, o Estatuto da Criança e do Adolescente prevê que a autoridade competente poderá aplicar as seguintes medidas socioeducativas: (a) advertência; (b) reparação do dano; (c) prestação de serviços à comunidade; (d) liberdade assistida; (e) regime de semiliberdade; (f) internação em estabelecimento educacional; $(\mathrm{g})$ encaminhamento aos pais ou responsável, mediante termo de responsabilidade; (h) orientação, apoio e acompanhamento temporários; (i) matrícula e frequência obrigatórias em estabelecimento oficial de ensino fundamental; (j) inclusão em programa comunitário ou oficial de auxílio à família, à criança e ao adolescente (art. 112, Lei n. 8.069/90). Os critérios de definição da espécie de medida são previstos nos parágrafos primeiro e segundo do referido artigo - " [...] a medida aplicada ao adolescente levará em conta a sua capacidade de cumpri-la, as circunstâncias e a gravidade da infração [...]" (BRASIL, 1990, art. 112, § $1^{\mathrm{o}}$, ) -, sendo vedadas formas cruéis de sanção - “[...] em hipótese alguma e sob pretexto algum, será admitida a prestação de trabalho forçado [...]" (BRASIL, 1990a, art. 112, § $2^{\circ}$ )

De acordo com a sistemática do sistema punitivo, é possível verificar que o Estatuto da Criança e do Adolescente ampliou de forma considerável as hipóteses de sanções não privativas de liberdade em sintonia com o preceito constitucional de diversificação das formas de intervenção.

É possível, portanto, após a descrição dos preceitos legais relativos às distintas áreas de intervenção, apresentar as espécies de penas e medidas previstas no sistema jurídico brasileiro aplicadas aos autores de atos ilícitos.

Destaque-se que na exposição de motivos do Código Penal o tratamento ambulatorial é considerado como medida restritiva, distinta da detentiva (internação): “[...] duas espécies de medida de segurança consagra o Projeto: a detentiva e a restritiva. A detentiva consiste na internação em hospital de custódia e tratamento psiquiátrico [...]. O Projeto consagra significativa inovação ao prever a medida de segurança restritiva, consistente na sujeição do agente a tratamento ambulatorial, cumprindo-lhe comparecer ao hospital nos dias que lhe forem determinados pelo médico, a fim de ser submetido à modalidade terapêutica prescrita." (EXPOSIÇÃO DE MOTIVOS DA REFORMA DO CÓDIGO PENAL, 1984, art. 89-90) 


\begin{tabular}{|c|c|c|c|}
\hline $\begin{array}{l}\text { Destinatários } \rightarrow \\
\text { Espécies de } \\
\text { Sanções } \downarrow\end{array}$ & Imputáveis & $\begin{array}{l}\text { Inimputáveis } \\
\text { Psíquicos } \\
\text { (Portadores de So- } \\
\text { frimento Psíquico) }\end{array}$ & $\begin{array}{c}\text { Inimputáveis Etários } \\
\text { (Adolescentes em Confli- } \\
\text { to com a Lei) }\end{array}$ \\
\hline $\begin{array}{l}\text { Sanções Privativas } \\
\text { de Liberdade }\end{array}$ & $\begin{array}{l}\text { Pena de reclusão ou } \\
\text { de detenção (art. 33, } \\
\text { caput, CP) em regi- } \\
\text { me: } \\
\text { (a) fechado (art. } 33, \S \\
1^{\circ}, \text { a, CP) } \\
\text { (b) semiaberto (art. } \\
33, \S 1^{\circ}, \text { b, CP) ou } \\
\text { (c) aberto (art. } 33, \S \\
\left.1^{\circ}, \mathrm{c}, \mathrm{CP}\right)\end{array}$ & $\begin{array}{l}\text { (a) Internação em } \\
\text { hospital de custódia } \\
\text { e tratamento psiqui- } \\
\text { átrico (art. 96, II, } \\
\text { CP) }\end{array}$ & $\begin{array}{l}\text { (a) Internação em es- } \\
\text { tabelecimento educa- } \\
\text { cional (art. 112, VI, Lei } \\
8.069 / 90 \text { ) } \\
\text { (b) Regime de semili- } \\
\text { berdade (art. 112, V, Lei } \\
8.069 / 90 \text { ) }\end{array}$ \\
\hline $\begin{array}{l}\text { Sanções Restritivas } \\
\text { de Direitos }\end{array}$ & $\begin{array}{l}\text { (a) Prestação de ser- } \\
\text { viço à comunidade ou } \\
\text { a entidades públicas } \\
\text { (art. } 43, \mathrm{IV}, \mathrm{CP} \text { ) } \\
\text { (b) Interdição tempo- } \\
\text { rária de direitos (art. } \\
43, \mathrm{~V}, \mathrm{CP} \text { ) } \\
\text { (c) Limitação de final } \\
\text { de semana (art. 43, } \\
\text { VI, CP) }\end{array}$ & $\begin{array}{l}\text { (a) Sujeição a trata- } \\
\text { mento ambulatorial } \\
\text { (96, II, CP) }\end{array}$ & $\begin{array}{l}\text { (a) Advertência (art. 112, } \\
\text { I, ECA) } \\
\text { (b) Prestação de serviços } \\
\text { à comunidade (art. 112, } \\
\text { III, ECA) } \\
\text { (c) Liberdade assistida } \\
\text { (art. 112, IV, ECA) } \\
\text { (d) Encaminhamento aos } \\
\text { pais (art. 101, I, ECA) } \\
\text { (e) Orientação, apoio e } \\
\text { acompanhamento (art. } \\
\text { 101, II, ECA) } \\
\text { (f) Frequência em estabe- } \\
\text { lecimento de ensino (art. } \\
\text { 101, IIII, ECA) } \\
\text { (g) Inclusão em programa } \\
\text { comunitário ou oficial } \\
\text { de auxílio (art. 101, IV, } \\
\text { ECA) }\end{array}$ \\
\hline Sanções Pecuniárias & $\begin{array}{l}\text { (a) Multa (art. 49, CP) } \\
\text { (b) Prestação pecuniá- } \\
\text { ria (art. 43, I, CP) } \\
\text { (c) Perda de bens (art. } \\
43, \text { II, CP)* }\end{array}$ & Sem previsão & $\begin{array}{l}\text { (a) Reparação do dano } \\
\text { (art. 112, I, ECA) }\end{array}$ \\
\hline
\end{tabular}

Quadro 1: Comparativo de espécies de sanções previstas para imputáveis e inimputáveis Fonte: Elaborado pelos autores deste artigo

* Embora o artigo 43 do Código Penal classifique a prestação pecuniária e a perda de bens e valores como penas restritivas de direito, o caráter monetário das sanções permite 
Importante lembrar que estas espécies de sanções referidas acima que revelam a tensão existente no interior do sistema jurídico entre as formas privativas de liberdade e as alternativas desinstitucionalizantes - são aplicáveis ao ato decisório que constata a prática de ato ilícito. Trata-se de possibilidades sancionatórias que o ordenamento jurídico fornece ao juiz no momento da sentença final, ou seja, após a instrução e com objetivo de encerrar o processo, seja o processo penal ou infracional.

Significa, portanto, que não estão incluídos, no rol apresentado acima, os institutos previstos no nosso ordenamento como (a) medidas alternativas ao processo de instrução ou como (b) possibilidades de flexibilização, na execução das penas e medidas, das formas de execução privativa de liberdade.

Em relação às alternativas ao processo, o Estatuto da Criança e do Adolescente, antecipando a reforma processual de 1995, prevê a possibilidade de concessão de remissão. Nos termos do artigo 126, o representante do Ministério Público, antes do início do procedimento judicial (art. 126, caput), ou o juiz, durante a instrução (art. 126, parágrafo único), poderão conceder a remissão como forma de exclusão, extinção ou suspensão do processo. Segundo o dispositivo legal, a remissão poderia, inclusive, possibilitar o cumprimento de alguma medida análoga desde que não representasse sanção privativa de liberdade (semiliberdade e internação). ${ }^{11} \mathrm{E}$ conforme destaca o artigo 127 da Lei n. 8.069/90, a concessão da remissão não pode produzir quaisquer efeitos relativos ao reconhecimento ou comprovação da responsabilidade e não gera qualquer efeito em termos de antecedentes.

identificá-las com a multa. Todavia, importante referir que diferentemente da multa, que é paga ao Fundo Penitenciário Nacional (Código Penal, 1940, art. 49), ou seja, possui destinação pública, a prestação pecuniária é destinada à vítima, nos termos do artigo 45 , $\S 1^{\circ}$, Código Penal.

11 Apesar da previsão legal, “[...] doutrina e jurisprudência assentaram as teses de que a remissão na modalidade como forma de exclusão do processo, concedida pelo Ministério Público, não pode vir cumulada com medida socioeducativa, por ofensa ao devido processo legal." (SHECAIRA, 2008, p. 214). A matéria foi sumulada pelo Superior Tribunal de Justiça: "[...] a aplicação de medidas socioeducativas ao adolescente pela prática de ato infracional é de competência exclusiva do juiz.” (SÚMULA 108) 
A remissão guarda interessante semelhança com os institutos diversificadores introduzidos no processo penal brasileiro pela Lei n. 9.099/95. Em relação à remissão pré-processual, concedida pelo Ministério Público e aplicada antes do oferecimento da representação, cujo efeito é a extinção do processo, João Batista Saraiva refere que

[...] se constituiu em inovação importante, cuja esteira veio a ser trilhada, em relação a determinados delitos praticados por imputáveis, pela Lei 9.099/95, que consagrou o instituto da transação penal no sistema penal adulto brasileiro. (SARAIVA, 2010, p. 226)

Quanto à remissão aplicada pelo Juiz da Infância e da Juventude, após a representação e durante a instrução, Shecaira (2008, p. 215) percebe que "[...] nestas duas espécies, suspensão e extinção do procedimento, guardam-se certa similitude com o instituto da suspensão condicional do processo, da Lei 9.099/95."

Os critérios de comparação são plenamente válidos, pois os institutos da Lei n. 8.069/90 e da Lei n. 9.099/95 objetivam, fundamentalmente, evitar que o autor do fato seja submetido ao processo (infracional ou penal). Remissão, composição civil, transação penal e suspensão condicional do processo constituem-se como mecanismos aptos a

[...] desviar os autores de atos delituosos do sistema estigmatizante da justiça criminal, o que projeta a discussão do 'problema criminal' para fora do processo, sento adotadas soluções informais e não institucionais. (SHECAIRA, 2008, p. 215)

Seja em relação aos atos infracionais (remissão), às infrações penais de menor potencial ofensivo (composição civil e transação penal) ou aos crimes comuns (suspensão condicional do processo), o Estatuto da Criança e do Adolescente e a Lei dos Juizados Especiais Criminais avançaram no sentido de efetivar os princípios constitucionais de subsidiariedade da intervenção punitiva. 
$\mathrm{Na}$ Justiça Criminal, na esfera dos Juizados Especiais Criminais ${ }^{12}$, em audiência preliminar, há possibilidade de o autor do fato e a vítima acordarem sobre formas de reparação do dano (composição civil, art. 72 da Lei n. 9.099/95 ${ }^{13}$ ). Não ocorrendo a composição civil ou sendo caso de crime sem vítima imediata, o Ministério Público tem a possibilidade de oferecer a transação penal (art. 76 da Lei n. 9.099/9514). Fora do âmbito dos Juizados Especiais Criminais, nos casos em que a lei penal prevê ao crime pena mínima não superior a um ano, o representante do Ministério Público poderá ${ }^{15}$ oferecer a suspensão condicional do processo (art. 89 da Lei n. 9.099/95). Conforme destacado, os institutos mencionados guardam estreita relação com a remissão, visto serem orientados pelos

[...] critérios de oralidade, informalidade, economia processual e celeridade, objetivando, sempre que possível, a reparação dos danos sofridos pela vítima e a aplicação de pena não privativa de liberdade. (BRASIL, 1995, art. 62)

12 “Art. 60 O Juizado Especial Criminal, provido por juízes togados ou togados e leigos, tem competência para a conciliação, o julgamento e a execução das infrações penais de menor potencial ofensivo, respeitadas as regras de conexão e continência.

Art. 61 Consideram-se infrações penais de menor potencial ofensivo, para os efeitos desta Lei, as contravenções penais e os crimes a que a lei comine pena máxima não superior a 2 (dois) anos, cumulada ou não com multa."

13 “Art. $72 \mathrm{Na}$ audiência preliminar, presente o representante do Ministério Público, o autor do fato e a vítima e, se possível, o responsável civil, acompanhados por seus advogados, o Juiz esclarecerá sobre a possibilidade da composição dos danos e da aceitação da proposta de aplicação imediata de pena não privativa de liberdade."

14 “Art. 76 Havendo representação ou tratando-se de crime de ação penal pública incondicionada, não sendo caso de arquivamento, o Ministério Público poderá propor a aplicação imediata de pena restritiva de direitos ou multas, a ser especificada na proposta." 15 Apesar do tempo verbal referido na Lei n. 9.099/05 (poderá), a doutrina e a jurisprudência consolidaram entendimento de que os institutos diversificadores não são benefícios ou favores legais ofertados discricionariamente pelo Ministério Público ou pelo Judiciário. Ao contrário, constituem-se como direitos públicos subjetivos do acusado. 


\begin{tabular}{|l|l|l|}
\hline $\begin{array}{l}\text { Institutos } \\
\text { Diversifica- } \\
\text { cionistas } \downarrow\end{array}$ & $\begin{array}{l}\text { Imputáveis e Inimputáveis } \\
\text { Psíquicos (Portadores de } \\
\text { Sofrimento Psíquico) }\end{array}$ & $\begin{array}{c}\text { Inimputáveis Etários } \\
\text { (Jovens em Conflito com a } \\
\text { Lei) }\end{array}$ \\
\hline $\begin{array}{l}\text { Fase Pré-processual } \\
\text { (antes do oferecimento da da } \\
\text { denúncia ou da representação) }\end{array}$ & $\begin{array}{l}\text { (a) Composição civil (art. 71, } \\
\text { Lei 9.099/95) } \\
\text { (b) Transação Penal (art. 76, } \\
\text { Lei 9.099/95) }\end{array}$ & $\begin{array}{l}\text { (a) Remissão (art. 126, caput, } \\
\text { ECA) }\end{array}$ \\
$\begin{array}{l}\text { Fase Processual } \\
\text { (após o oferecimento da da } \\
\text { denúncia ou da representação) }\end{array}$ & $\begin{array}{l}\text { (a) Suspensão condicio- } \\
\text { nal do processo (art. 89, Lei } \\
9.099 / 95) .\end{array}$ & $\begin{array}{l}\text { (a) Remissão (art. 126, pará- } \\
\text { grafo único, ECA) }\end{array}$ \\
\hline
\end{tabular}

Quadro 2: Comparativo de espécies de alternativas processuais previstas para imputáveis (processo penal) e inimputáveis (processo infracional)

Fonte: Elaborado pelos autores deste artigo

Associadas aos procedimentos de diversificação pré-processual (remissão, composição civil, transação e suspensão condicional do processo) encontram-se as formas de suspensão ou de flexibilização das penas e das medidas socioeducativas.

Da mesma forma que o Código Penal prevê a possibilidade de: (a) não execução da pena privativa de liberdade ou restritiva de direito (suspensão condicional da pena); (b) modificação da situação do apenado ao longo da execução através da transferência de regimes mais graves para outros com maiores espaços de liberdade (progressão de regime) ou inclusive; (c) o condenado terminar o cumprimento da pena em liberdade (livramento condicional), o Estatuto da Criança e do Adolescente prevê formas de obstaculizar ou minimizar o impacto da internação.

A liberdade assistida, espécie de medida socioeducativa (BRASIL, 1990a, art. 112, IV) cumpre esta função de maneira autônoma ou subsidiária. Como forma autônoma,

[...] trata-se de um substitutivo penal, à semelhança do sistema do probation system, e que, na legislação aplicável aos adultos, recebeu o nome de suspensão condicional da pena (sursis). (SHECAIRA, 2008, p. 200) 
Em realidade, a autonomia do instituto é ampla, atuando como instrumento de obstaculização do processo de instrução (remissão) e como medida socioeducativa exclusiva, constituindo-se sanção executada em meio aberto. No entanto, pode constituir-se, como o livramento condicional (CÓDIGO PENAL, 1940, art. 83), em uma etapa final da execução da medida socioeducativa, integrando o sistema de progressão da privação de liberdade. Neste quadro, a liberdade assistida pode integrar a terceira etapa de execução, após a progressão do regime de internação para a semiliberdade ou, aplicada diretamente sem necessidade da etapa intermediária, como substitutivo pleno da internação.

O Estatuto da Criança e do Adolescente prevê duas espécies de medidas socioeducativas privativas de liberdade. A espécie mais grave de sanção aplicável ao adolescente condenado pelo ato infracional é a medida de internação (BRASIL, 1990b, art. 121-125) - forma de execução pouco distinta da pena privativa de liberdade cumprida em regime fechado. O regime de semiliberdade - análogo ao cumprimento de pena em regime semiaberto - pode ser aplicado como etapa inicial ou intermediária de transição para o meio aberto (progressão da medida), nos termos do artigo 120 da Lei n. 8.072/90. Em ambos os casos, porém, atua como mais uma alternativa à excepcionalidade da privação absoluta.

Note-se que a forma progressiva prevista para as penas e as medidas socioeducativas tem correspondência na execução das medidas de segurança, seja através dos procedimentos de desinternação ou de liberação condicional (CÓDIGO PENAL, 1940, art. 97, § $3^{\text {o16 }}$ ) ou da transferência da modalidade de internação psiquiátrica para o tratamento ambulatorial (alta progressiva ${ }^{17}$ ).

\footnotetext{
16 “Art. 97 - Se o agente for inimputável, o juiz determinará sua internação (art. 26). Se, todavia, o fato previsto como crime for punível com detenção, poderá o juiz submetê-lo a tratamento ambulatorial [...].

$\S 3^{\circ}$ A desinternação, ou a liberação, será sempre condicional devendo ser restabelecida a situação anterior se o agente, antes do decurso de 1 (um) ano, pratica fato indicativo de persistência de sua periculosidade." (CÓDIGO PENAL, 1940)

17 Não há previsão legal para a alta progressiva. Esta forma de progressão da medida de segurança em regime de internação para o ambulatorial é uma construção jurisprudencial que atualmente tem sido universalizada no sistema jurídico-penal nacional.
} 


\begin{tabular}{|c|c|c|c|}
\hline $\begin{array}{l}\text { Mecanismos } \\
\text { diversificadores } \downarrow\end{array}$ & Pena & Medida de Segurança & $\begin{array}{l}\text { Medida Socioedu- } \\
\text { cativa }\end{array}$ \\
\hline $\begin{array}{l}\text { Suspensão da Execução } \\
\text { (aplicação antes do iní- } \\
\text { cio do cumprimento da } \\
\text { pena ou da medida) }\end{array}$ & $\begin{array}{l}\text { (a) Suspensão con- } \\
\text { dicional da pena } \\
\text { (art. } 77, \mathrm{CP} \text { ) }\end{array}$ & Sem previsão & $\begin{array}{l}\text { (a) Liberdade assis- } \\
\text { tida (art. 118, Lei n. } \\
8.069 / 90)\end{array}$ \\
\hline $\begin{array}{l}\text { Flexibilização da Exe- } \\
\text { cução (aplicação du- } \\
\text { rante o cumprimento } \\
\text { da pena ou da medida) }\end{array}$ & $\begin{array}{l}\text { (a) Progressão de } \\
\text { regime (art. 33, ca- } \\
\text { put, CP); e } \\
\text { (b) Livramento } \\
\text { condicional (art. } \\
\text { 83, CP) }\end{array}$ & $\begin{array}{l}\text { (a) Desinternação ou libe- } \\
\text { ração condicional (art. 97, } \\
\left.\S 3^{\circ}, \mathrm{CP}\right) \text {; e } \\
\text { (b) Alta progressiva } \\
\text { (construção jurispruden- } \\
\text { cial em analogia ao art. } \\
33 \text {, caput, CP) }\end{array}$ & $\begin{array}{l}\text { (a) Progressão da } \\
\text { medida (art. 120, } \\
\text { ECA); e } \\
\text { (b) Liberdade assis- } \\
\text { tida (art. 118, ECA) }\end{array}$ \\
\hline
\end{tabular}

Quadro 3: Comparativo de instrumentos legais de suspensão, substituição ou progressão das sanções (penas e medidas) privativas de liberdade

Fonte: Elaborado pelos autores deste artigo

\section{Penas e Medidas Restritivas de Direito: sobre a prestação de serviço à comunidade}

A análise do sistema jurídico brasileiro de penas e medidas (socioeducativas e de segurança) permite perceber a existências de inúmeros instrumentos legais de diversificação penal e processual, institutos que objetivam resguardar as sanções privativas de liberdade apenas para os casos mais graves, efetivando normativamente a ideia de intervenção punitiva subsidiária (ou de ultima ratio).

Os mecanismos legais alternativos atuam em quatro distintos momentos. Em primeiro, na fase pré-processual, por meio da propositura de alternativas ao processo com a composição civil, a transação penal e a remissão. No segundo momento, após o oferecimento da denúncia ou da representação, em uma fase processual pré-julgamento, com a suspensão condicional do processo e novamente com a possibilidade de remissão. $\mathrm{O}$ terceiro momento ocorre na fase de julgamento, quando o juiz, em caso de condenação, pode suspender a sanção (sursis) ou substituir suas formas carcerárias (pena privativa de liberdade ou internação) por penas ou 
medidas alternativas (penas restritivas de direito ou penas pecuniárias). Na quarta etapa, durante o processo de execução da pena ou da medida, o juiz responsável tem a possibilidade de aplicar instrumentos flexibilizadores (progressão de regime, progressão de medida, alta progressiva) ou substitutivos (livramento condicional, liberdade assistida, conversão das penas privativas de liberdade em restritivas de direito), com a mudança da situação jurídica do condenado.

A criação desta série de ferramentas diversificacionistas e a sua gradual incorporação pelo direito brasileiro a partir da Reforma Penal de 1984, sobretudo após a Constituição de 1988, derivaram diretamente das evidências apresentadas pelo paradigma criminológico do etiquetamento, posteriormente consolidadas pela criminologia crítica, no que tange aos efeitos deteriorizadores provocados pelas instituições totais (prisões, manicômios judiciários e casas correcionais juvenis). A crítica criminológica desnudou os efeitos perversos dos modelos carcerários a partir do confronto entre os discursos oficiais (funções prometidas) e as práticas institucionais concretas (funções ocultas). Demonstrou, assim, a distorção entre as finalidades de promoção da ressocialização (pena), do tratamento (medida de segurança) e da educação (medida socioeducativa) e a efetivação radicalizada da violência institucional em seus procedimentos estigmatizadores e moralizantes de anulação das identidades.

A série de medidas diversificacionistas (processuais ou punitivas) deriva dos projetos de alternativas ao cárcere. Nesta especificidade, a ideia de trabalho em benefício da comunidade é ressaltada, sobretudo, pelo seu potencial não dessocializador (BITENCOURT, 2011, p. 572). As modalidades não privativas de liberdade ganham relevância na justiça penal juvenil em face de que

[...] as medidas impostas a adolescente e crianças, quando configuravam institucionalizações, têm os efeitos deteriorantes das instituições totais agravados de uma maneira considerável, porque a deterioração institucional costuma produzir efeitos mais permanentes num indivíduo jovem do que em um adulto; uma vez empreendida, seja com o nome que for, pode provocar estragos irreversíveis, pois não opera no efeito regressivo com que atua sobre o adulto, mas 
sim de modo diretamente impeditivo da aprendizagem da sociabilidade mais ou menos comum da pessoa. (ZAFFARONI et al. 2003, p. 315)

No direito internacional dos direitos humanos, o marco de efetivação das medidas alternativas ao cárcere são as Regras de Tóquio, publicadas no $8^{\circ}$ Congresso da Organização das Nações Unidas (1990).

O documento procurou criar um conjunto de orientações dos Estados-membros para a promoção e a implementação de medidas não privativas de liberdade substitutivas à prisão

[...] as presentes regras têm por objetivo promover uma maior participação da comunidade na administração da justiça penal e, muito especialmente, no tratamento do delinquente, bem como estimular entre os delinquentes o senso de responsabilidade em relação à sociedade. (BRASIL, 1990c, art. 1.2)

Assim, apesar de o documento manter o discurso correcionalista, define uma pauta político-criminal em que os Estados-membos se obrigam a introduzir medidas não privativas de liberdade em seus sistemas jurídicos

[...] as condições da medida devem ser práticas, precisas e tão poucas quanto possíveis, e terão por objetivo reduzir as possibilidades de reincidência do comportamento delituoso e incrementar as possibilidades de reintegração social do delinquente. (BRASIL, 1990c, art. 9.1)

Logicamente, a consolidação do plano de reforma global dos sistemas punitivos é fruto de uma longa tradição do direito internacional de gradual implementação de penas substitutivas. Ensina Bitencourt (2011, p. 551) que as penas substitutivas à prisão, na modalidade de prestação de serviços à comunidade, foram criadas pelo Código Penal soviético de 1926, sendo posteriormente reproduzidas nos ordenamentos penais do leste europeu e transnacionalizadas ao Ocidente - Bélgica (1963), França (1970), Alemanha (1975), Itália (1975), Portugal (1977) e Espanha 
(1980). O entendimento prevalecente de que "[...] a experiência com o sistema institucional resultou, sabidamente, negativa, restando a prisionalização como deletéria, até porque componente causal da reincidência." (THOMPSON, 1991, p. 5), projetou a tentativa de "[...] humanizar o Direito Penal recorrendo a novas medidas que não o encarceramento." (REALE JR., 1999, p. 48)

$\mathrm{Na}$ legislação brasileira pós-Constituição, o Estatuto da Criança e do Adolescente é o primeiro texto que inova nas modalidades de sanções restritivas de direitos e consolida a prestação de serviço à comunidade como pena alternativa por excelência (BRASIL, 1990a, art. 112), pois

[...] essa sanção representa uma das grandes esperanças penológicas, ao manter o estado normal do sujeito e permitir, ao mesmo tempo, o tratamento ressocializador mínimo, sem prejuízo de suas atividades laborais normais. (BITENCOURT, 2011, p. 575)

$\mathrm{Na}$ legislação penal dos adultos, a reforma operada pela Lei n. 9.714/98 igualmente ampliou o rol de penas substitutivas, definindo, no artigo 43 do Código Penal, como espécies de penas restritivas de direito, a prestação pecuniária, a perda de bens e valores, a prestação de serviço à comunidade ou a entidades públicas, a interdição temporária de direitos e a limitação de fim de semana. Outrossim, a Lei das Penas Alternativas estendeu os requisitos de aplicação, prevendo a possibilidade de substituir a pena carcerária pela restrição de direitos em quaisquer hipóteses de condenação por crime culposo e nos casos de condenação a pena privativa de liberdade não superior a quatro anos, quando presentes circunstâncias favoráveis ao réu. (CÓDIGO PENAL, 1940, art. 44)

O Estatuto da Criança e do Adolescente define que a prestação de serviço à comunidade

[...] consiste na realização de tarefas gratuitas de interesse geral, por período não excedente a seis meses, junto a entidades assistenciais, hospitais, escolas e outros estabelecimentos congêneres, bem como em programas comunitários ou governamentais. (BRASIL, 1990a, art. 117) 
Como prevê o artigo 46 do Código Penal, os serviços em benefício da comunidade devem constituir-se na atribuição de tarefas gratuitas em áreas adequadas às aptidões dos adolescentes e de forma que não prejudiquem a frequência à escola ou a jornada de trabalho. Além disso, segundo o parágrafo único do artigo 117 do Estatuto da Criança e do Adolescente, o cumprimento não pode ultrapassar oito horas semanais.

Shecaira $(2008$, p. 199) sustenta que a prestação de serviço à comunidade deve ser a principal pena alternativa às penas institucionais, no âmbito da justiça penal de adultos e de adolescentes, pois induz no

[...] infrator a ideia de responsabilidade, de apego às normas comunitárias, de respeito pelo trabalho, bem como produz na comunidade uma sensação de obediência às regras, que é fundamental para a confiança coletiva.

Não restam dúvidas, pelos estudos específicos no campo das penas e das medidas alternativas e pela experiência acumulada pela Justiça brasileira nas duas últimas décadas, que a prestação de serviços à comunidade representa uma das melhores formas de resposta ao ilícito. Entenda-se esta virtude dos trabalhos em benefício à comunidade como fruto de uma concepção teórica e política que prima pela constante e gradual constrição do uso das formas privativas de liberdade e que busca possibilidades concretas de reduzir os danos provocados pela ingerência violenta das agências de punitividade, notadamente as carcerárias.

Após mais de meio século de críticas ao uso do encarceramento como sanção prioritária, é possível perceber a inabilidade dos poderes públicos em gerir os conflitos sociais. Inabilidade que resulta em uma espiral de ampliação da violência dos ilícitos pela violência da resposta ao ilícito. Não por outra razão, a partir do desvelamento da crise dos múltiplos sistemas de prisionalização, surgem instrumentos que potencializam o envolvimento da sociedade civil na resolução dos conflitos gerados na comunidade.

Certamente isto não significa que o Estado deve estar ausente deste processo. A judicialização do processo de instrução e de execução das medidas socioeducativas representou um notório avanço no sistema de 
garantias, com a negação das formas punitivas produzidas a partir da ideologia da situação irregular e do abandono material e moral que, conforme destacam Zaffaroni et al. (2003, p. 315)

[...] atribuiu às penas o nome de medidas e eliminou os controles judiciais e os limites liberais sob o pretexto de tutela. Desta maneira impôs plenamente o princípio inquisitório, com todas as suas consequências penais de fundo e de processo.

Espécies de penas restritivas como a prestação de serviço à comunidade permitem, pois, que ao mesmo tempo se estabeleçam o controle judicial (garantista) da legalidade da medida e o envolvimento entre o adolescente e a sociedade na gestão do conflito.

Embora tensa a relação entre punir e educar, a experiência do envolvimento e do acolhimento comunitários dos adolescentes em conflito com a lei pode gerar efeitos altamente positivos, desde que o jovem se sinta "[...] co-participante no próprio processo de desenvolvimento", e "reconhecido como alguém que merece consideração." (CRAIDY; GONÇALVES, 2003, p. 2). Garantir que os adolescentes (e os adultos) em conflito com a lei sejam atores de sua história é o pressuposto de um modelo que nega o segregacionismo inquisitório das tradicionais formas punitivas.

Desde essa perspectiva é possível desenvolver práticas pedagógicas de valorização da pessoa. Valorização que ocorre quando o sujeito

...] se sente produtivo, útil, aceito, exigido, integrado num ambiente organizado onde as regras são claras, tem acesso a novos conhecimentos e encontra uma perspectiva de vida. (CRAIDY; GONÇALVES, 2003, p. 4)

\section{Conclusões}

A hipótese central comungada por inúmeros autores da crítica criminológica é a de que a política dos substitutivos penais não rompe com a 
lógica carcerocêntrica. Ao contrário, os substitutivos atuariam como elementos de reprodução e de relegitimação das políticas de encarceramento.

Stanley Cohen (apud MATHIESEN, 1989, p. 115) aponta para os efeitos maximizadores do controle punitivo/carcerário ínsitos aos modelos de diversificação:

[...] os distintos estudos nos Estados Unidos, Canadá e Inglaterra demonstram que as alternativas ao cárcere não são válidas. Pelo contrário, convertem-se em 'adicionais/somatórios', seja pelo fato de aumentar o número de pessoas sob controle social formal, seja por somar mais do que reduzir o sistema de controle formal. As 'alternativas' propostas tendem claramente a "estender a rede" [...]

Nils Christie (1984, p. 151) demonstra que

[...] as experiências recentes como "opções de encarceramento" indicam que facilmente se convertem em "prolongamentos do encarceramento" e que as sanções condicionais em realidade convertem-se em maior tempo de cárcere.

As hipóteses sustentadas por Cohen e Christie na década de 1980, período em que os institutos diversificacionistas passaram a integrar as legislações penais dos países ocidentais, foram validadas e comprovadas por recentes pesquisas acadêmicas realizadas no Brasil. (CARVALHO, 2010)

Nesse cenário em que as penas restritivas de direito, especialmente a prestação de serviço à comunidade, apresentam inquestionáveis virtudes como instrumento de redução dos danos gerados pelo encarceramento, é necessário afirmar as alternativas à prisão e à internação como efetivas alternativas e não como sistemas adicionais, apêndices ou válvulas de escape do insolvente modelo de privação de liberdade. Devem constituir-se, portanto, como possibilidades reais de minimizar a dor do encarceramento, estabelecendo radical ruptura com a lógica carcerocêntrica. qual

Do contrário, estaremos diante de uma preocupante armadilha na 
[...] os substitutos penais não enfraquecem a prisão, mas a revigoram; não diminuem sua necessidade, mas a reforçam; não anulam sua legitimidade, mas a ratificam: são instituições tentaculares cuja eficácia depende da existência revigorada da prisão, o centro nevrálgico que estende o poder de controle, com a possibilidade do reencarceramento se a expectativa comportamental dos controlados não confirmar o prognóstico dos controladores. (SANTOS, 1985, p. 299)

O debate responsável sobre os níveis de prisionalização e sobre os efeitos amplificadores dos substitutivos penais deve, necessariamente, enfrentar tais questões, sobretudo se o objetivo é efetivamente diminuir os enormes danos que o encarceramento em massa de adolescentes, jovens e adultos tem produzido em termos de custos de vidas humanas no Brasil.

$\mathrm{Na}$ realidade prisional brasileira contemporânea pode-se observar que a institucionalização das penas e das medidas alternativas não restringiu os níveis de prisionalização, pelo contrário, as taxas, a partir da década de 1990, vêm crescendo gradual, constante e superlativamente.

As preocupações positiva, com a ampliação dos direitos, e negati$v a$, com a limitação dos poderes, constituem-se em parâmetro metodológico que permite estabelecer condições de possibilidade prático-teóricas de reinvenção humanizadora das modalidades de sanção, com a projeção concreta da utopia da superação das formas carcerárias.

Nas palavras de Rauter (1997, p. 73), a conclusão:

[...] considero que estar preso - seja num hospital psiquiátrico ou numa prisão - é algo inaceitável para um ser humano, e um discurso que sustente a desarticulação destes espaços me soa como algo que deve ser valorizado.

\section{Referências}

BITENCOURT, Cezar. Falência da pena de prisão: causas e alternativas. São Paulo: RT, 1993. 
. Tratado de direito penal, 16. ed. São Paulo: Saraiva, 2011.

(v. 1)

BRASIL. Código Penal. Colaboração de Antonio L. de Toledo Pinto, Márcia V. dos Santos Wíndt e Lívia Céspedes. 39. ed. São Paulo: Saraiva 2001, 794 p.

. Constituição da República Federativa do Brasil de 1988.

Disponível em: < http:/www.planalto.gov.br/ccivil_03/constituicao/ constitui\%C3\%A7ao.htm>. Acesso em: 24 maio 2012.

. Decreto-Lei n. 2.848, de 7 de dezembro de 1940. Institui o Código Penal. Disponível em: < http://www.planalto.gov.br/ccivil_03/ decreto-lei/del2848.htm>. Acesso em: 24 maio 2012.

. Lei n. 8.069, de 13 de julho de 1990a. Dispõe sobre o Estatuto da Criança e do Adolescente e dá outras providências. Disponível em: $<$ http://www.planalto.gov.br/ccivil_03/leis/L8069.htm>. Acesso em: 24 maio 2012.

. Lei n. 8.072, de 25 de julho de 1990b. Dispõe sobre os crimes hediondos, nos termos do art. $5^{\circ}$, inciso XLIII, da Constituição Federal, e determina outras providências. Disponível em: $<$ http://www.planalto.gov. br/ccivil_03/leis/L8072.htm>. Acesso em: 24 maio 2012.

. Ministério da Justiça. Secretaria Nacional de Justiça. Normas

e Princípios das Nações Unidas sobre Prevenção ao Crime e Justiça Criminal. Brasília - DF, 1990c.

. Lei n. 9.099, de 26 de setembro de 1995. Dispõe sobre os Juizados Especiais Cíveis e Criminais e dá outras providências. Disponível em: <http://www.planalto.gov.br/ccivil_03/leis/L9099.htm>. Acesso em: 24 maio 2012.

CARVALHO, Salo. Antimanual de criminologia. Rio de Janeiro: Lumen Juris, 2011.

. Pena e garantias. Rio de Janeiro: Lumen Juris, 2001.

. Substitutivos Penais na Era do Grande Encarceramento. In:

Criminologia e sistemas jurídico-penais contemporâneos II. Porto Alegre: EDIPUCRS, 2010. 
- Teoria Agnóstica da Pena. In: Crítica à execução penal. Rio de Janeiro: Lumen Juris, 2007.

COYLE, Andrew. Alternatives to imprisionment. Londres: EAI, 1999. CRAIDY, Carmen Maria; GONÇALVES, Liana Lemos. Elementos para uma Pedagogia das Medidas Socioeducativas. In: Medidas socioeducativas: da repressão à educação. Porto Alegre: UFRGS, 2003.

CHRISTIE, Nils. Los limites del dolor. Cidade do Mexico: Fondo de Cultura Económica, 1984.

GARLAND, David. The culture of control: crime and social order in contemporary society. Oxford: Oxford University Press, 2001.

QUEIROZ, Paulo. Direito penal: parte geral. 7. ed. Rio de Janeiro: Lumen Juris, 2011.

MATHIESEN, Thomas. La Politica del Abolicionismo. In: Abolicionismo. Buenos Aires: Ediar, 1989.

PORTUGAL. Constituição (1976). Constituição da República Portuguesa. Lei do Tribunal Constitucional. Coordenação, J. J. Gomes Canotilho e Vital Moreira. 8. ed. Coimbra: Coimbra, 2005.

RAUTER, Cristina. Manicômios, Prisões, Reformas e Neoliberalismo.

Discursos Sediciosos, v. 3. Rio de Janeiro: Revan/Instituto Carioca de Criminologia, 1997.

REALE Jr., Miguel. Mens Legis Insana, corpo estranho. In: REALE Jr., Miguel et al. Penas restritivas de direitos. São Paulo: Revista dos Tribunais, 1999.

ROSA, Alexandre Morais. Introdução crítica ao ato infracional. Rio de janeiro: Lumen Juris, 2007.

SANTOS, Juarez Cirino dos. Direito penal (a nova parte geral). Rio de Janeiro: Forense, 1985.

SARAIVA, João Batista Costa. Compêndio de direito penal juvenil. 4 . ed. Porto Alegre: Livraria do Advogado, 2010. 
SHECAIRA, Sérgio Salomão. Sistema de garantias e o direito penal Juvenil. São Paulo: Revista dos Tribunais, 2008.

THOMPSON, Augusto. Escorço histórico do direito criminal luso-brasileiro. São Paulo: RT, 1976.

ZAFFARONI, Eugenio Raul et al. Direito penal brasileiro I. Rio de Janeiro: Revan, 2003. 